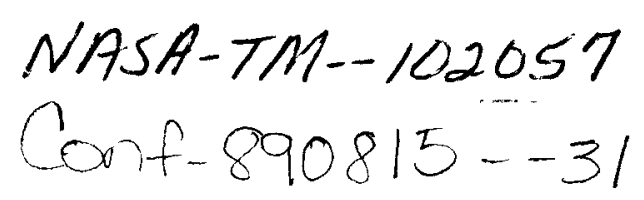

NASA Technical Memorandum 102057

\title{
Two-Dimensional Numerical Simulation of a Stirling Engine Heat Exchanger
}

\author{
Mounir B. Ibrahim \\ Cleveland State University \\ Cleveland, Ohio
}

and

Roy C. Tew and James E. Dudenhoefer

Lewis Research Center

Cleveland, Ohio

Prepared for the

24th Intersociety Energy Conversion Engineering Conference cosponsored by the IEEE, AIAA, ANS, ASME, SAE, ACS, and AIChE Washington, D.C., August 6-11, 1989

\section{DISCLAIMER}

This report was prepared as an account of work sponsored by an agency of the United States Government. Neither the United States Government nor any agency thereof, nor any of their employees, makes any warranty, express or implied, or assumes any legal liability or responsibility for the accuracy, completeness, or usefulness of any information, apparatus, product, or process disclosed, or represents that its use would not infringe privately owned rights. Reference herein to any specific commercial product, process, or service by trade name, trademark, manufacturer, or otherwise does not necessarily constitute or imply its endorsement, recommendation, or favoring by the United States Government or any agency thereof. The views and opinions of authors expressed herein do not necessarily state or reflect those of the United States Government or any agency thereof. 


\section{DISCLAIMER}

This report was prepared as an account of work sponsored by an agency of the United States Government. Neither the United States Government nor any agency Thereof, nor any of their employees, makes any warranty, express or implied, or assumes any legal liability or responsibility for the accuracy, completeness, or usefulness of any information, apparatus, product, or process disclosed, or represents that its use would not infringe privately owned rights. Reference herein to any specific commercial product, process, or service by trade name, trademark, manufacturer, or otherwise does not necessarily constitute or imply its endorsement, recommendation, or favoring by the United States Government or any agency thereof. The views and opinions of authors expressed herein do not necessarily state or reflect those of the United States Government or any agency thereof. 


\section{DISCLAIMER}

Portions of this document may be illegible in electronic image products. Images are produced from the best available original document. 
TWO-DIMENSIONAL NUMERICAL SIMULATION OF A STIRLING ENGINE HEAT EXCHANGER

\author{
Mounir Ibrahim \\ Cleveland State University \\ Cleveland, Oh10 44115
}

Roy C Tew and James E Dudenhoefer

NASA Lewis Research Center

Cleveland. Ohro 44135

\begin{abstract}
This paper describes the first phase of an effort to develop multidimensional models of Stirling engine components, the uitimate goal is to model an entire engine working space More specifically, this paper describes parallel plate and tubular heat exchanger models with emphasis on the central part of the channel ( $1 \mathrm{e}$, ignoring hydrodynamic and thermal end effects) The model assumes laminar, incompressible flow with constant thermophysical properties In addition, a constant axial temperature gradient 15 imposed The governing equations, describing the model, have been solved using Crack-Nicloson finite-difference scheme Model predictions have been compared with analytical solutions for oscillating/reversing flow and heat transfer in order to check numerical accuracy The simplifying assumptions will later be relaxed to permit modeling of compressible, laminar/turbulent flow that occurs in Stirling heat exchanger

Excellent agreement has been obtained for the model predictions with analytical solutions avallable for both flow in circular tubes and between parallel plates Also the heat transfer computational results are in good agreement with the heat transfer analytical results for parallel plates

\section{NOMENCLATURE}

$d p / d x$ axial pressure gradient, $\mathrm{N} / \mathrm{m}^{3}$

f time-averaged Fanning friction factor $=$

$$
2 \sqrt{\overline{\tau_{w}^{2}}} / \rho \overline{u_{a v}^{2}}
$$

$f_{S}$ unidirectional Fanning friction factor

$\begin{array}{ll}\text { Pr } & \text { Prandtl number } \\ 0 & \text { pressure, } \mathrm{N} / \mathrm{m}^{2} \\ \mathrm{Re} & \text { Reynolds number }=2 \mathrm{U}_{\mathrm{av}}\left(\mathrm{R}_{\mathrm{O}}-\mathrm{R}_{1}\right) / v \\ R_{1} & \text { half width of the channel, } \mathrm{m} \\ R_{0} & \begin{array}{l}\text { half distance between two consecutive } \\ \text { plates, } \mathrm{m}\end{array} \\ r \quad & \begin{array}{l}\text { radial location, measured from channel } \\ \text { centerline, } \mathrm{m}\end{array}\end{array}$
\end{abstract}

$\alpha_{e} \quad$ effective averaged thermal diffusivity. 'the thermal diffusivity that will produce the same axial heat flux as obtained from radial conduction and axial convection heat transfer" =

$-\frac{\omega}{2 \pi \lambda\left(R_{0}-R_{1}\right)} \int_{0}^{2 \pi / \omega} \int_{R_{1}}^{R_{0}} T u d y d t, m^{2} / s$

$\alpha_{e}^{*} \quad$ normalized effective averaged thermal diffusivity $=\alpha_{e} /\left(\omega J x^{2}\right)$

$\Delta x \quad$ tidal displacement 'the cross-streamaveraged maximum axial distance which the fluid elements travel during one half period of oscillation" =

$\frac{1}{R_{0}-R_{1}} \int_{0}^{\pi / \omega} \int_{R_{1}}^{R_{0}} u d y d t$.

$\begin{array}{ll}\Delta x^{*} & \text { normalized tidal displacement }=\Delta x /\left(\mathrm{u}_{0} / \omega\right) \\ \frac{\partial T}{\partial x}=\lambda & \text { axial temperature gradient, } \mathrm{k} / \mathrm{m} \\ \mu & \text { fluid dynamic viscosity, } \mathrm{kg} / \mathrm{m} / \mathrm{s} \\ \nu & \text { fluid } \mathrm{kinematic} v i s \cos 1 \mathrm{ty}, \mathrm{m}^{2} / \mathrm{s} \\ \rho & \text { density, } \mathrm{kg} / \mathrm{m}^{3}\end{array}$




\author{
$\tau_{N}$ wall shear stress, $\mathrm{V} / \mathrm{m}^{2}$ \\ $\$$ pressure gradient phase angle, (deg) \\ $=\omega t(360 / 2 \pi)$ \\ $\omega$ frequency, $\mathrm{rad} / \mathrm{s}$ \\ $\omega^{*} \quad$ Valensi number $=\left[\omega\left(R_{0}-R_{1}\right)^{2}\right] / v$
}

\section{INTRODUCTION}

NASA is developing free-piston Stirling engines for space power generation These engines are designed with computer codes which simulate the oscillating/reversing flow and oscillating pressure level using one-dimensional flow analyses Confidence is lacking in the resulting characterizations of the various interrelated thermodynamic losses For example, the use of steady-flow friction factor and heat transfer correlations throughout the engine working space is of questionable validity

It has not been possible to make accurate in-englne measurements of flows, velocities, temperatures and pressure drops However, several oscillating-flow rigs are being used to learn more about engine fluld mechanics and heat transfer via dynamic measurements Multidimensional modeling 15 another process for achleving better understanding of fluid flow and heat transfer phenomena in Stirling engine working spaces Such models can be used to study velocity and temperature fields within the engine components, these fields can then be compared with the fields $1 \mathrm{mplied}$ by use of the one-dimensional correlations Heat transfer and fluld friction can also be calculated and compared with correlation assumptions used in onedimensional codes It may be possible to validate portions of multidimensional models directly with data from the oscillating flow rigs Cleveland State University, with support from NASA Lewis Research Center, is working on development of multidimensional models of Stirling engine components The first stage of this work, reported here, 15 development of a two-dimensional model of parallel plate and tubular heat exchangers

One problem encountered by use of any numerical code is the evaluation of the errors in the solution due to the inherently approximate numerical techniques A practical approach to evaluating such errors is to compare the numerical solution for a restricted version of the problem to an exact analytical solution This paper reports on comparison of parallel plate heat exchanger model predictions with an exact analytical solution developed by Kurzweg [1] Kurzweg's solution is for oscillating flow between parailel plates with heat transfer

\section{ANALYSIS}

\section{Assumptions}

Figure 1 shows a sketch of the channel flow vith the computation domain and boundary conditions The following assumptions were made
(1) The flow is laminar incompressible and has constant theimophysical properties

(2) Since we are only concerned with the fluld flow in the central part ( 1 in the $1-d i r e c t i o n)$ of the channel, hydrodynamic and thermal end effects can be ignored This assumption can be satisfied by using a long channel compared to 1 ts width

(3) As a consequence to assumption (2) all convection terms in the momentum and energy equations can be ignored, except for the ou(aT/ax) term in the energy equation, since it is the only convective driving mechanism for the heat transfer

(4) The axial temperature gradient 15 constant This assumption is consistent with the experimental finding for a similar setup [2] where it was found that the temperature laries linearly with $x$ in almost 80 percent of the central length of the channel

(5) Under the oscillating flow conditions, heat transfer is controlled by radial conduction and axial convection Therefore the axial heat conduction can be ignored

\section{Governing Equations}

Applying the above assumptions to the general form of the Navier Stokes equations ylelds the foilowing set of equations

Continuity

$$
\frac{\partial u}{\partial x}=0
$$

$\underline{x-M o m e n t u m}$

$$
\rho \frac{\partial u}{\partial t}=-\frac{d p}{d x}+\frac{1}{r^{\prime}} \frac{\partial}{\partial r}\left(r^{\prime} \mu \frac{\partial u}{\partial r}\right)
$$

Energy

$$
\rho \frac{\partial T}{\partial t}=-\rho U \frac{\partial T}{\partial x}+\frac{1}{r^{1}} \frac{\partial}{\partial r}\left(r^{1} \frac{\mu}{\rho r} \frac{\partial T}{\partial r}\right)
$$

where $1=1$ for circular tubes

$$
=0 \text { for flow between parallel plates }
$$

The code developed is capable of predicting both circular tube flow and flow between parallel plates, however, the results provided in this paper are only for parallel plates

The pressure gradient term in Eq (2) is assumed to be of oscillatory nature according to

$$
\frac{d p}{d x}=\left(\frac{d p}{d x}\right)_{\max } \cos \omega t
$$

The above equations are subjected to the following boundary conditions 


$$
\left.\begin{array}{llll}
\text { from } & r=R_{0} & \text { to } & R_{1} \quad u=0, \\
\text { at } & r=R_{0} & \frac{\partial T}{\partial r}=J \quad \text { and } \\
\text { at } & r=0 & \frac{\partial u}{\partial r}=\frac{\partial T}{\partial r}=0
\end{array}\right\}
$$

Since the computation domain includes both the solid and the fluld, the boundary condition at the solid/fluid interface is automatically satisfied

It should be noted that the above boundary conditions have been carefully selected for the following reasons

(1) They match the boundary conditions given in Kurzweg's [1] analysis Accordingly, the numerical results can be compared with his analytical solution

(2) The above boundary conditions to great extent could simulate the central element (from both axial and radial directions) of a Stirling engine foll regenerator

\section{Numerical Method}

The above partial differential equations have been transformed into finite difference equations using different schemes, namely, fully explicit, Crank Nicoison and fully implicit A sensitivity analysis was conducted by comparing the results from each finite difference scheme with the fluid flow analytical solution It was concluded that the Crank Nicolson scheme is the most accurate, this is consistent $w i$ th other research findings for unsteady heat equation problems [3]

\section{RESULTS}

\section{Comparison with Analytical Solution}

One of the main objectives of this work is to develop an accurate and efficient numerical scheme that can be used with confidence in future engine models Therefore, an extensive grid variation test was conducted for both space and time to obtain grid independent and accurate numerical results

Table I shows the normalized tidal displacement and normalized effective thermal diffusivity as obtained for water $(\mathrm{Pr}=1026)$ with $R_{0}=2 R_{1}$ and the assumption that the solid has the same thermophysical properties as the fluid In the table the present work numerical predictions were compared with the analytical solution [1] for $\omega^{*}$ from 009 to 9 The numerical results showed the same trend where a maximum $\alpha_{e}^{*}$ occurs at $\omega^{*}=0306$ as indicated by the analytical solution for $\operatorname{Pr}=1026$ Table I shows differences between the numerical and analytical results of less than 20 percent

Furthermore, the present work velocity profiles for different fluids (water and air) were checked against the corresponding anal/tical velocties at several radial locations Figures $2(a)$ (b), and (c) show the numerical velocity lersus the andivtrca one at various iddial locations $n$ the channel (near wall region, $y / R_{0}=J 506$, ha $f$ distance between the wall and centerline $y / R_{0}=075$, and centerline, $\left.y / R_{0}=10\right)$ Results are shown for water, $\omega^{\star}=0306$ (Fig $\left.2(a)\right)$, water, $\omega^{*}=90$ (Fig 2(b)), and air, $\omega^{*}=448$ (Fig 2(c)) The plots show, again the close agreement betreen the numerical and analytical solutions

\section{Fluid Flow Results}

\section{Velocity profile}

Figures $3(a),(b)$, and (c) show the dimensionless velocity profile $u^{*}$ versus the dimensionless distance $\left(y / R_{0}\right)$ for water, $\omega^{*}=0306\left(F_{1 g} 3(a)\right)$,

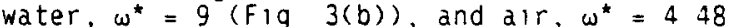
( $F$ ig $3(c)$ ) Upon examining the above figures the following were noted

(1) For low dimensionless frequency $\left(\omega^{*}=0\right.$ 306) the velocity profile has a maximum at the channel centerline

(2) As $\omega^{*}$ increases a boundary layer starts to develop near the solid surface

(3) Aiso, as $\omega^{*}$ increases the flow direction near the wall becomes opposite to that in the core, in certain parts of the cycle

\section{Friction factor}

From the relocity profiles described above one can obtain wall shear stress, friction factor and Reynolds number at any pressure gradient phase angle In addition, a root-mean-square can be calculated for the wall shear stress as well as the mean cross-sectional axial velocity from the latter one can calculate friction factor and Reynolds number based upon time averaged quantities, similar to the work done on circular tubes by Chen and Griffin [4] Chen and Griffin had obtained a correlation for the normalized friction factor (w) th respect to the corresponding unidirectional flow), $f / f_{s}$, based upon an approximate velocity profile given by White [5] Work is underway to compare present work results with Chen and Griffin s correlation

\section{Heat Transfer Results}

In the channel flow under study, the maximum radial temperature difference, between the channel wall temperature and the bulk fluld temperature, can be obtained by ignoring the radial heat conduction Accordingly, this maximum radial temberature difference is equal to the axial temperature gradient times the tidal displacement Now, one can obtain a normalized temperature profile utiliz'ng the maximum radial temperature difference described above

Figures $4(a)$ and (b) show the normalized temperature profile versus $y / R_{0}$ for $\omega^{*}=3306$ 
water), and $\omega^{*}=4.48$ (air) at different pressure gracient phase angles $\phi$. It should be noted that the solid is represented in the region $y / R_{0}=0$ to 0.5 . The temperature fluctuation in the fluid is much larger, as expected, than it is in the solid. Also this ratio between those temperature fluctuations (in fluid/in solid) becomes greater as $\omega^{*}$ increases.

Finally, the maximum effective thermal diffusivity described above in Table I can be better explained by plotting both the velocity and temperature at the same radial location versus $\phi$. figures $5(a)$ and (b) show the normalized velocity and normalized temperature profiles versus $\phi$ at $y / R_{0}=0.506,0.75$ and 1.0 ; for $\omega^{*}=0.306$ (water), and $\omega^{\star}=4.48$ (air) respectively. It should be noted that the value of $\omega^{*}$ chosen for each fluid corresponds to the maximum $\alpha_{e}^{*}$ that can be obtained.

It can be seen from the plots that there is always a phase shift between the velocity and temperature profile. It is interesting to notice that the phase shift is almost the same for the above two cases examined. It is believed that this phase shift (approximately $120^{\circ}$ at $y / R_{0}=1.0$ ) provides the maximum interaction between axial convection and radial conduction and consequently the maximum net axial heat flux.

\section{CONCLUDING REMARKS}

An accurate numerical scheme has been applied to calculate the fluid flow and heat transfer characteristics in an oscillating channel flow. The flow was assumed laminar, incompressible and has constant thermophysical properties. Also a constant axial temperature gradient was imposed on the channel; however the axial heat conduction was assumed negligible.

The numerical scheme has been successful in predicting velocity profiles, tidal displacement, temperature profiles, and effective thermal diffusivity for a wide range of $\omega^{*}$ and different types of fluid (water and air). This shows that the present work numerical studies confirm earlier investigations.

The interaction between axial convection and radial conduction heat transfer, if tuned properly, would result in a considerable enhanced axial heat transfer. These tuned conditions, for the cases examined in the paper, occurred at $\omega^{*}=0.306$ (water) and $\omega^{*}=4.48$ (air). It is believed that the phase shift between the velocity and temperature profiles are tied in with this tuning process.
In a stirling engine regenerator, these conditions (at which maximum axial heat transfer occur) snould be avoided.

It should be noted that those tuned $\omega^{*}$ are restricted to the channel configuration and the different assumptions explained in the paper. A study is underway to examine other operating conditions (such as type of fluid, wall material, order of magnitude of axial pressure and temperature gradients, etc.) that are relevant to stirling engines.

This work is a first step in the planned development of a two-dimensional code which can be used to model stirling engine heat exchangerstubular heaters, tubular and foil type regenerators, and tubular coolers. As the studies continue, the simplifying assumptions will be changed to include laminar/turbulent flow, compressible working fluid, and different outer thermal boundary conditions.

A second study has begun to model the rapid expansion and contraction of oscillating flow entering and exiting the heat exchangers. This work will permit the incorporation of hydrodynamic and thermal end effect conditions to the heat exchanger model.

\section{REFERENCES}

1. U.H. Kurzweg, "Enhanced Heat Conduction in Oscillating Viscous Flows Within ParallelPlate Channels," J. Fluid Mech., vol. 156. pp. 291-300, 1985.

2. G. Zhang, "Time Dependent Enhanced Heat Transfer in Oscillating Pipe Flow," Ph.D. Thesis, University of Florida, 1988.

3. D.A. Anderson, J.C. Tannehill and R. H. Pletcher, Computational Fluid Mechanics and Heat Transfer. Washington, D.C.: Hemisphere Publishing Corp., 1984.

4. N.C.J. Chen and F.P. Griffin, "Effects of Pressure-Drop Correlations on Stirling Engine Predicted Performance," in Energy for the Marketplace (18th IECEC), vol. 2, New York: American Institute of Chemical Engineers, 1983, pp. 708-713.

5. F.M. White, Viscous Fluid Flow, New York: McGraw-Hill, 1974. 
TABLE I - COMPARISON GETWEEN PRESENT WORK NUMERICAL RESULTS FOR $\Delta x^{*}$ and $\alpha_{e}^{*}$ AND ANALYTICAL SOLJTION [1] FOR DIFFERENT $\omega$ * [Water $(\mathrm{Pr}=1026)$ and $R_{0} / R_{1}=20$ ]

\begin{tabular}{|l|c|c|c|c|}
\hline $\begin{array}{c}\text { Valens1 } \\
\text { number, } \\
\omega^{*}\end{array}$ & \multicolumn{2}{|c|}{$\begin{array}{c}\text { Normalized tidal displacement } \\
\Delta x^{*}\end{array}$} & $\begin{array}{c}\text { Normalized effective averaged } \\
\text { thermal diffusivity } \\
\alpha_{e}^{*}\end{array}$ \\
\cline { 2 - 5 } & Present work & Analytical [1] & Present Nork & Analytical [1] \\
\hline 009 & 005941 & 005995 & 002616 & 002568 \\
16 & 1055 & 1064 & 03707 & 03645 \\
25 & 1643 & 1658 & 04039 & 04029 \\
306 & 2019 & 2023 & 04051 & 03979 \\
10 & 6160 & 6181 & 02415 & 02302 \\
9 & 1607 & 161 & 00421 & 00386 \\
\hline
\end{tabular}




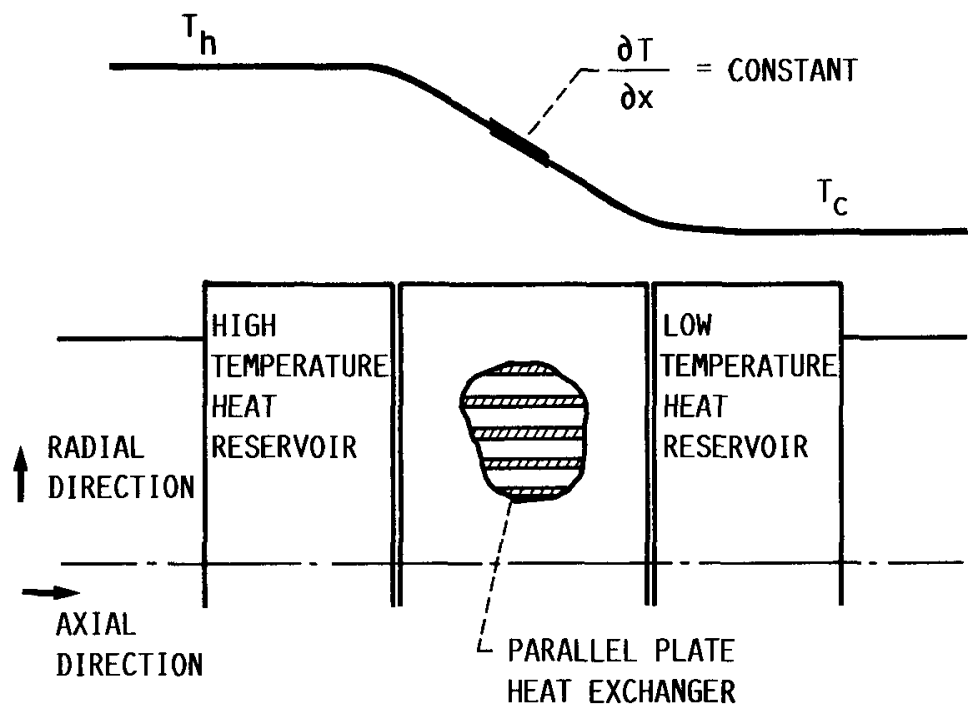

(a) SKETCH OF OVERALL SYSTEM.

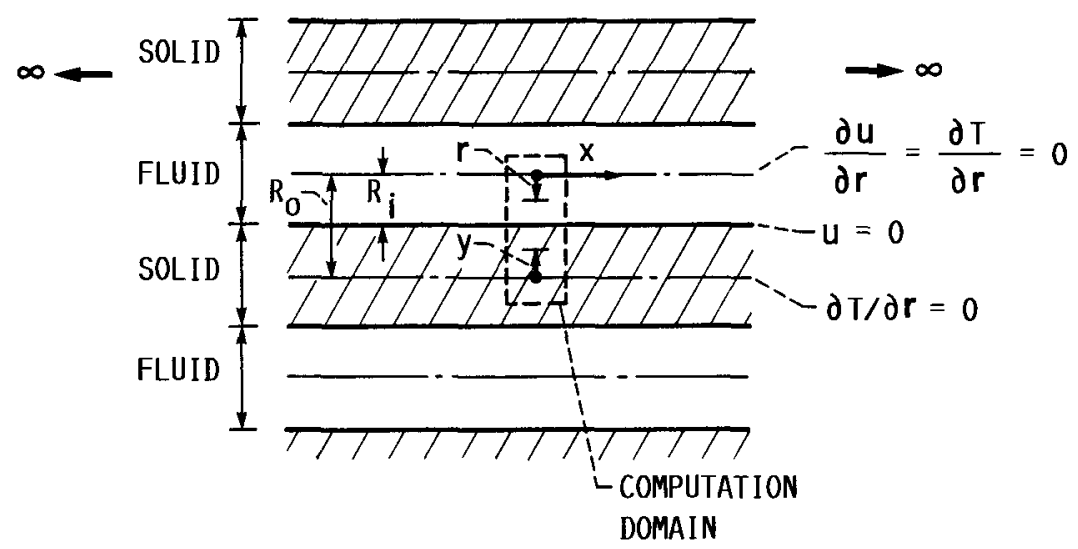

(b) CENTRAL PART SHOWING THE COMPUTATION DOMAIN AND BOUNDARY CONDITIONS.

FigURE 1. - SKETCH OF A PARALLEL PLATE hEAT EXCHANGER. 


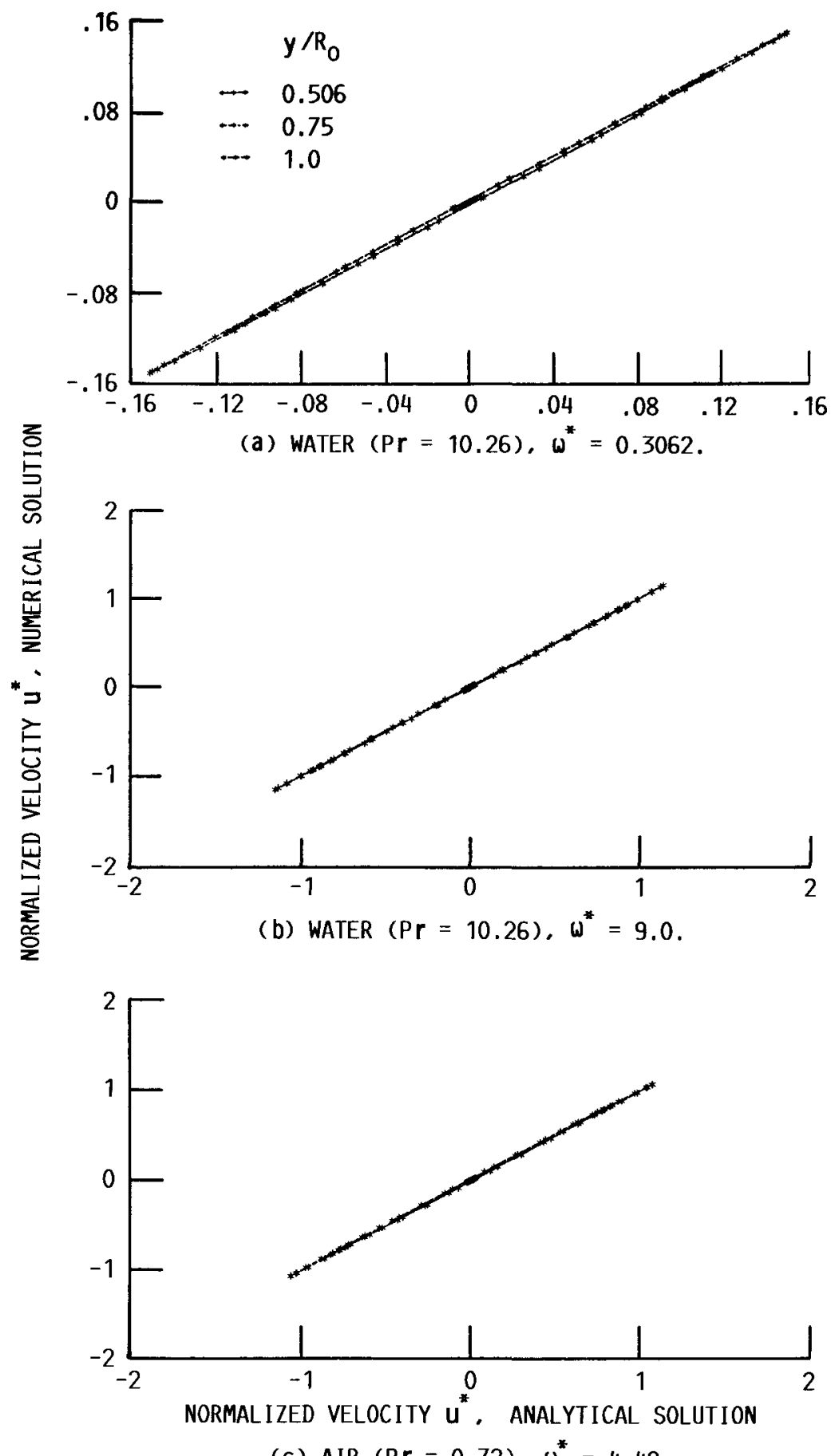

(c) AIR ( Pr $=0.72), \omega^{*}=4.48$.

FIGURE 2. - COMPARISON BETWEEN NUMERICAL AND ANALYTICAL VELOCITY PROFILES AT $y / R_{0}=0.506$ (NEAR WALL). 0.75 AND 1.0 (CENTERLINE) FOR $R_{0} / R_{i}=2.0$. (NOTE THAT THE DATA POINTS FOR DIFFERENT $Y / R_{0}$ ALMOST COINCIDE AND LIE ON A LINE AT $45^{\circ}$ WITH THE AXIS). 


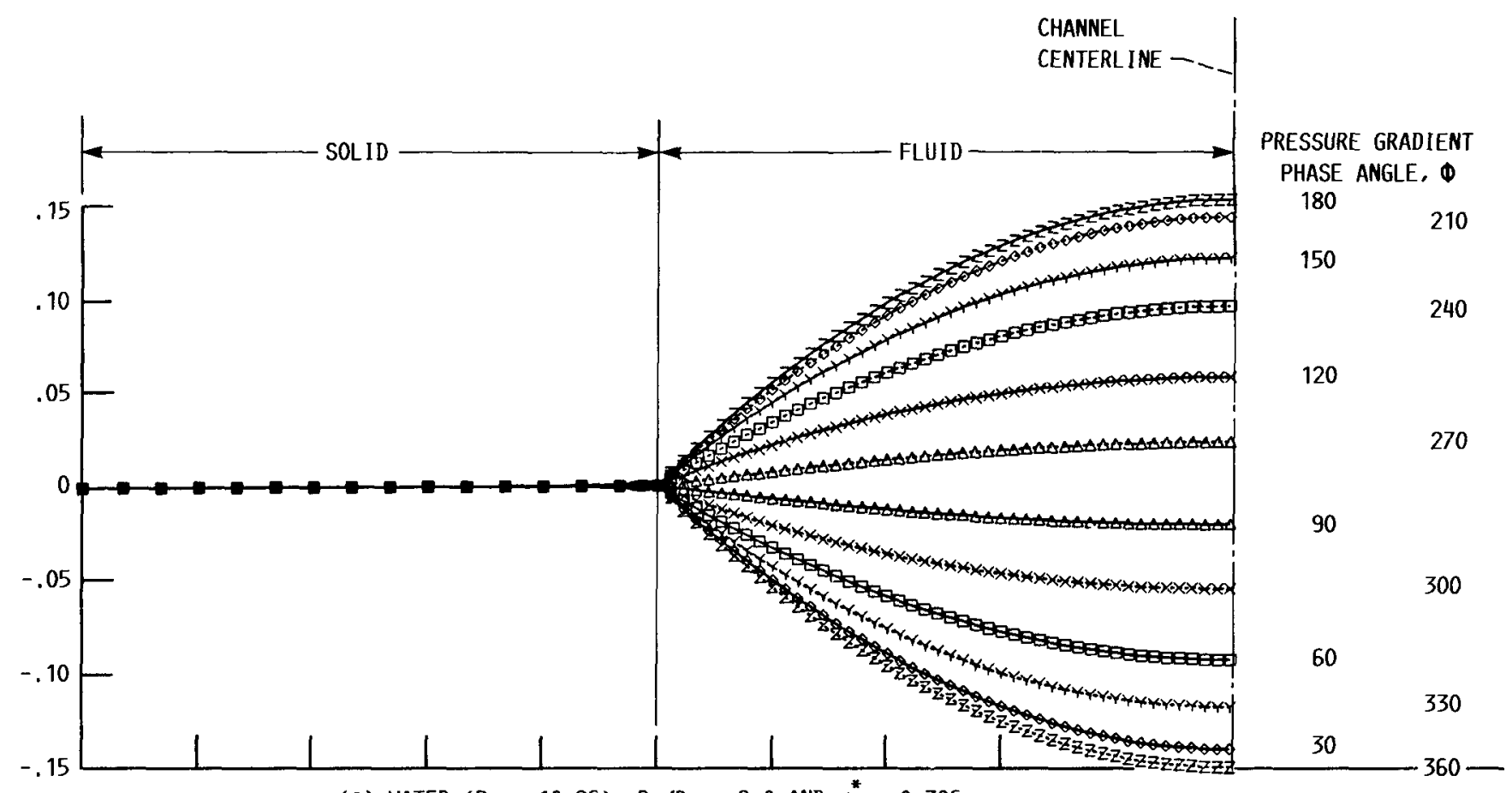

(a) WATER ( $\mathrm{Pr}=10.26), \mathrm{R}_{0} / \mathrm{R}_{\mathbf{i}}=2.0$ AND $\omega^{*}=0.306$.

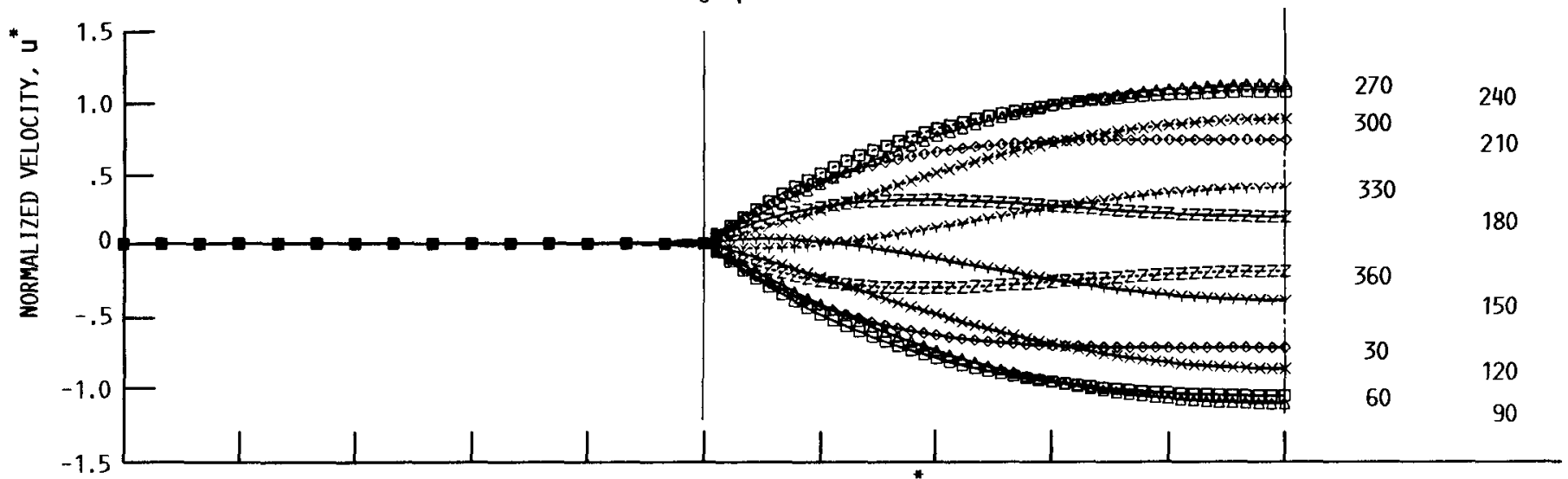

(b) WATER (Pr $=10.26), R_{0} / R_{i}=2.0$ AND $\omega^{*}=9.0$.

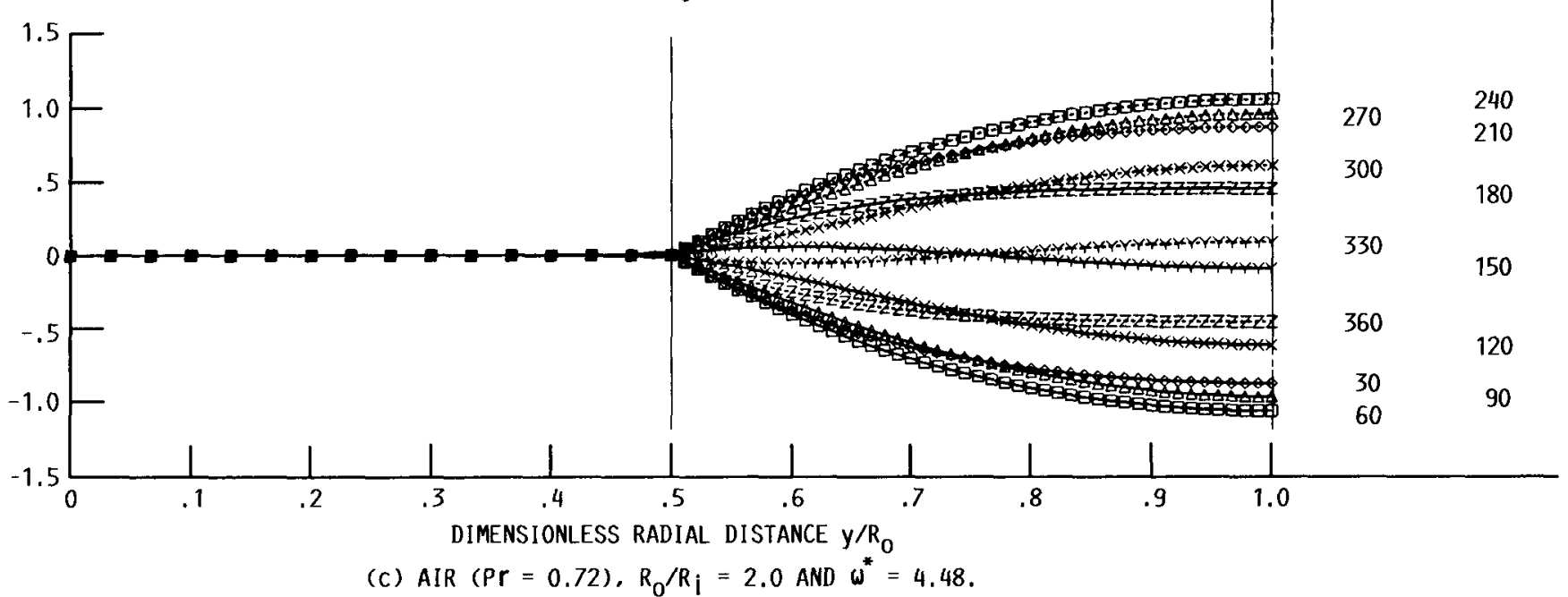

FIGURE 3. - NORMALIZED VELOCITY PROFILES VERSUS DIMENSIONLESS RADIAL DISTANCE AT DIFFERENT PRESSURE GRADIENT PHASE ANGLES. 


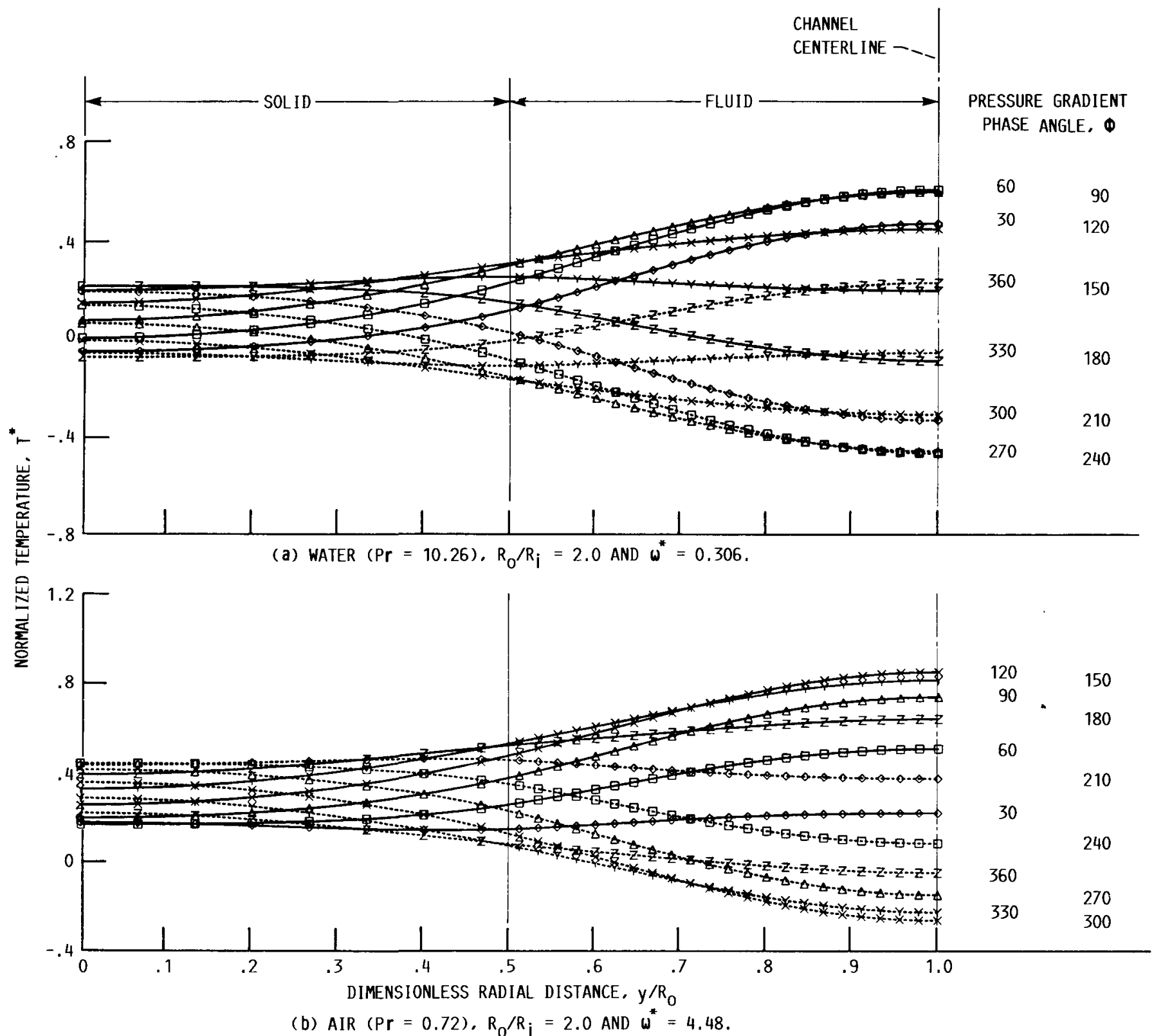

FIGURE 4. - NORMALIZED TEMPERATURE PROFILES VERSUS DIMENSIONLESS RADIAL DISTANCE AT DIFFERENT PRESSURE GRADIENT ANGLES. 


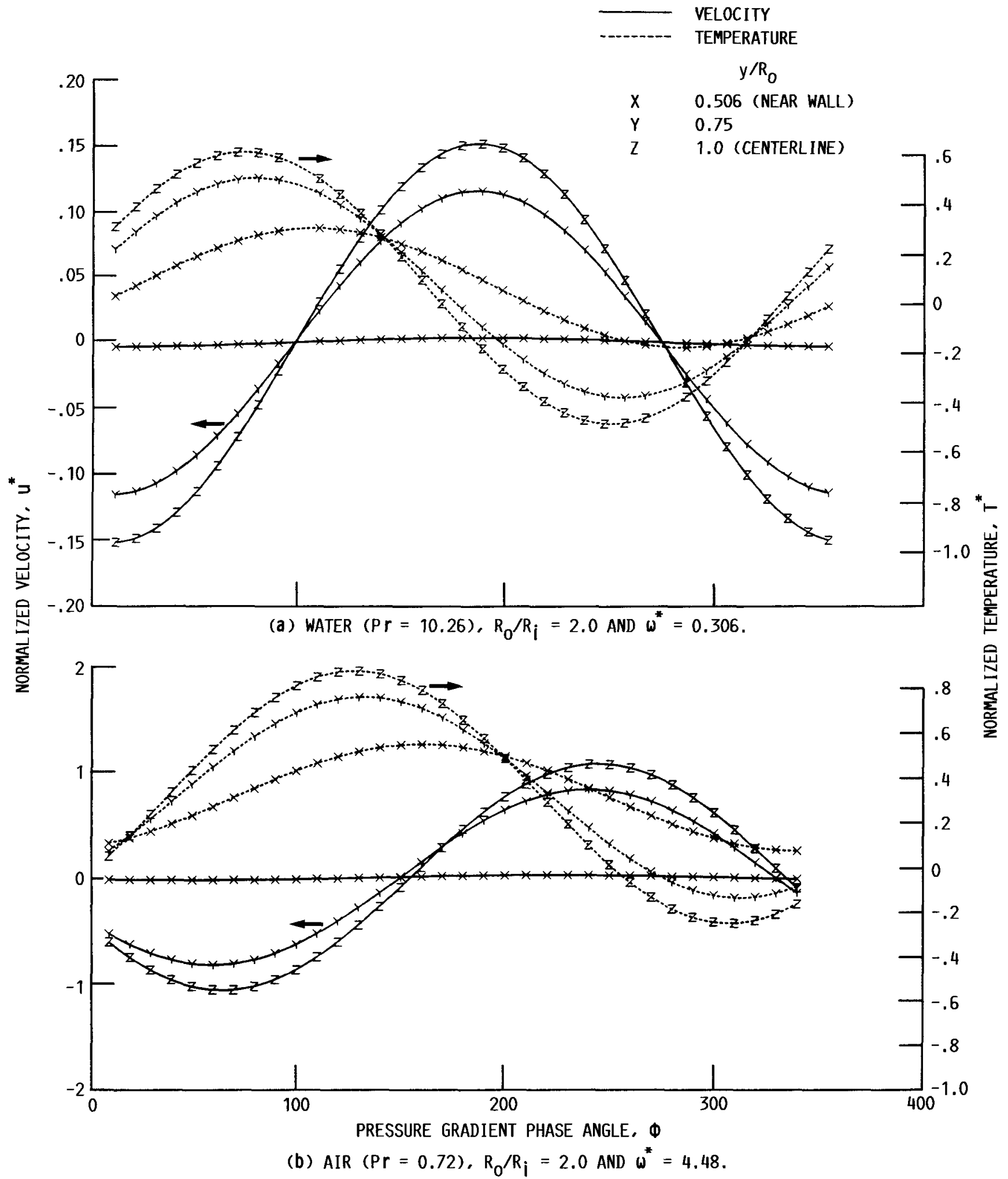

FIGURE 5. - NORMALIZED VELOCITY AND TEMPERATURE PROFILES VERSUS PRESSURE GRADIENT PHASE ANGLE AT DIFFERENT RADIAL DISTANCES $\left(y / R_{0}=0.506,0.75\right.$ AND 1.0). 


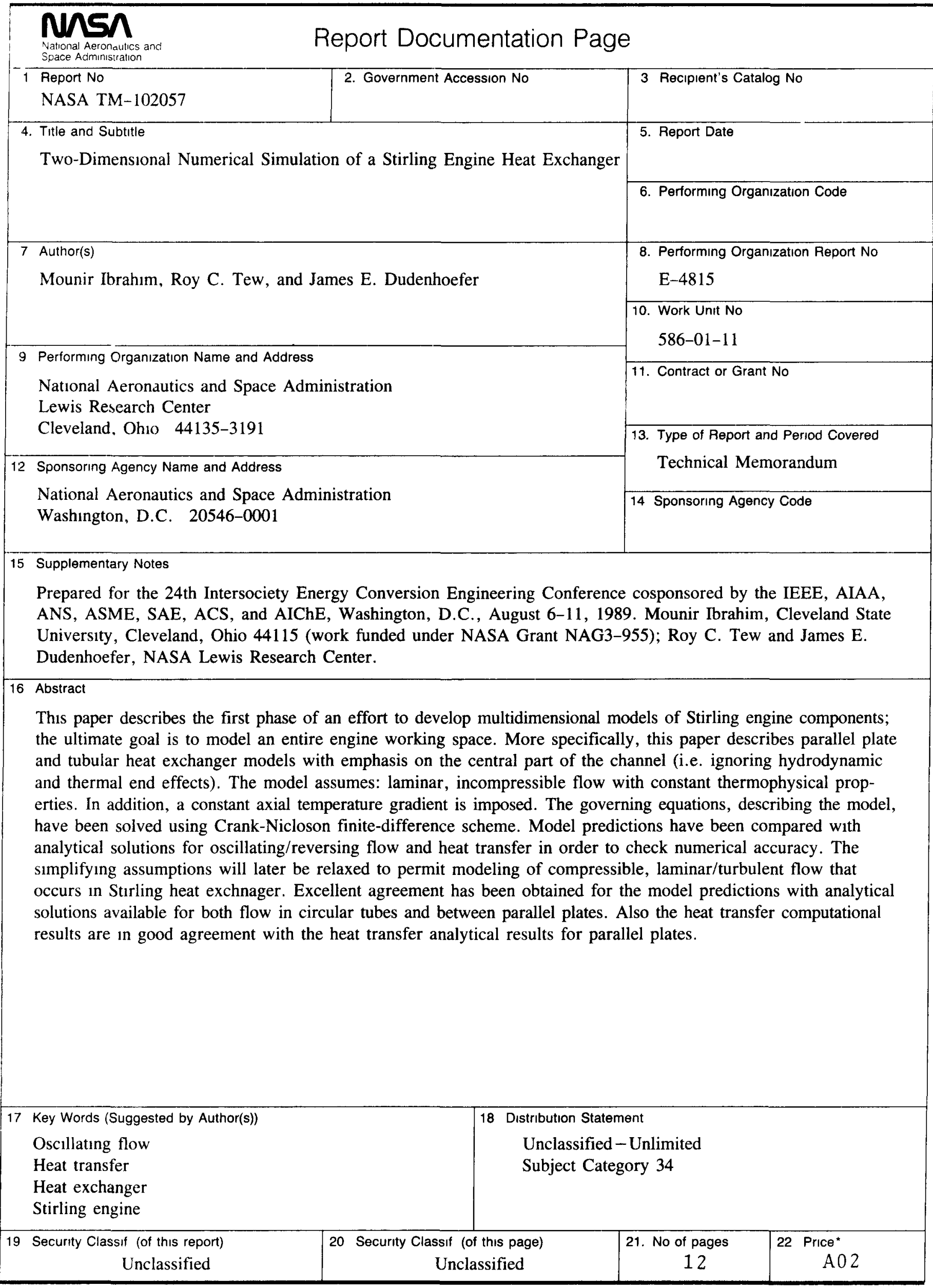


National Aeronautics and Space Administration

Lewis Research Center

Cleveland. Ohio 44135

Oncial Bumineses

Pencly bor Patrats Uas 1500
SECOND CLASS MAIL

ADDRESS CORRECTION REQUESTED

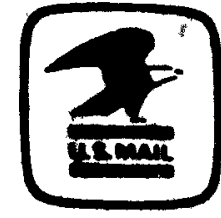

Poetage and Foes Paid Netional Aeronwutics and Spece Adminuatration MASA-451
J. Winter
MS 301-5 